\title{
Reform in the training of digestive surgeons in France: a revolution for a renaissance!
}

\author{
Karim Boudjema ${ }^{1} \cdot$ Laurent Sulpice $^{1}$
}

Received: 21 May 2019 / Accepted: 27 May 2019 / Published online: 17 June 2019

(C) Italian Society of Surgery (SIC) 2019

In France, digestive surgery is no longer popular and the best medical students no longer choose this specialty. Nowadays, the top-ranking students prefer to get into more "peaceful" surgical specialties and, let us admit it, more exciting too. They prefer surgical specialties with short procedures, consistent results, happy patients who show their gratitude, few on-call periods, i.e., a good and comfortable life with a very good salary. All of that is what now attracts students. The feminization of medical studies [1] (75\% of the students in Rennes are females) could perhaps explain this disenchantment but it is the way our profession is taught that should be called into question. The government has, therefore, undertaken a reform in the training of all specialists that came into force on November 1, 2018 in France [2-4].

Until last year, training for French digestive surgeons conformed to teaching practices that were in large part defined under Consul Bonaparte (décret consulaire du 4 ventôse an $\mathrm{X}, 22$ février 1802)! Such training is based on three principles: selection of the best, assumption of responsibility, and the buddy system. Indeed, medical students who, after 5 or 6 years of studies (every student has 2 chances to succeed), pass a very selective competitive residency examination become hospital residents overnight. This qualification provides them with a salary, the right to write prescriptions, and guarantees training based on practice in an academic environment. The learning of medical and surgical techniques is performed by the buddy system. The French term "compagnonnage" (buddy system) comes from French workers who monitor and help one another learn in stages through "buddies" who are experts. Like guilds of cathedral builders, "apprentice" acquisition of a surgical procedure is performed day after day under the guidance of a "Master" who, depending on if you are skilled or not, "allows" you

Karim Boudjema

karim.boudjema@chu-rennes.fr

1 Department of HBP and GI Surgery, Hôpital Pontchaillou, Université de Rennes1, Rennes, France to operate or not. Placements in surgical departments last 6 months and surgeons are trained 4-6 years (depending on whether the subspecialty residents choose or not). Four to six years of "monastic" life during which, the more time one spends in the hospital, the more one experiences and the more one learns by absorption. Like almost all of the digestive surgeons of my generation and those before it, it is the way i learned hepatobiliary and digestive surgery. Resident at age 22, i was selflessly, passionately anxious for any experience to enrich our "hard-core" training. I sacrificed everything for my work and perhaps that is the problem. Indeed, I believe that this way of learning, "traditional" and "constraint", has strongly contributed to the estrangement from our specialty by young residents who are aware that there is life outside the hospital. I have a lot of hope in the reform imposed by our lawmakers to restore the attraction that our specialty had for a long time.

Several factors incited the government to reform resident training, in particular, that of surgical residents. Above all, demand by patients who are better informed by the internet and social networks. They are more curious and now have legitimate demands. They want to know who is treating them, the level of training of the doctor, and in cases of surgery, who they are risking their lives with. Inexperience, no longer hidden by a white coat or a mask, is now easy to detect and no patient will accept treatment by an inexperienced practitioner. Another factor has been a demand by residents that they benefit from training that is more formal, more reproducible, better controlled, better organized, that guarantees their autonomy to practice at the end of their training. In that vein, one favoring factor has been the need to respect, even for surgical residents, European legislation on working time. Our residents have been working so far an average of $80 \mathrm{~h}$ a week. They work through sleepless nights without hesitation because their careers depend on it. According to the new European law, they have been offered a weekly work time of "only" $48 \mathrm{~h}$ with on-call time and 
compensatory rest time included! This drastic reduction in work time has obliged us to revise our mode of teaching.

In the so-called postgraduate degree reform, the title of resident has changed names. In the past, "doctor" (even if he or she had not yet received a diploma), today, the title is "doctor in training". This means that he or she practices surgery as a "student". This detail is of considerable importance in which it imposes teaching that is structured and graded to ensure that residents will be equipped to practice the career that they have chosen to learn.

For future surgeons, including digestive surgeons, the new postgraduate degree lasts 6 years and is broken down into three phases: a phase called "basics" with two semesters spent in different departments; then a phase called "deepening" that lasts six semesters; and finally, a phase called "consolidation" that lasts 2 years for a total of 6 years to obtain a "postgraduate diploma in visceral and digestive surgery".

The basics phase is an initiation to the basic theories and practices of general surgery. In particular, one learns how to manage digestive emergency and surgical assistance. It is also devoted to acquisition of general culture: anesthesia knowledge, intensive care, epidemiology and public health, health economics, infectiology, pharmacology of the agents currently used in our profession (antimitotics and antalgics); also training in human relations in a hospital, i.e., how to manage a conflictual situation with a patient or even (yes, it exists) with a member of the healthcare team; how to announce post-operative complications (who has not dreamt of how to tell a patient that he or she forgot a compress in the surgical site) or impending end of life; how to talk to a patient's family. My generation of surgeons was never taught these subjects and that is very regrettable. Acquiring this theoretical knowledge requires time and the reform reserves two half-days per week for this training. Two half-days where any contact with healthcare are forbidden. At the end of this basics year, the student is interviewed to evaluate his or her knowledge and assess his or her level of motivation to continue in this surgical specialty. In fact, all postgraduate students have a "right to regret" and can change specialty without losing this first year of basics. This is considerable progress. Indeed, I am sure that many teaching surgeons will recall meeting residents who obviously were not cut out for this job but had never accepted it or dared to talk about it. At the end of the basics phase, a contract is signed between the student and the university, which guarantees him a complete formation at the end of the third cycle.

The second phase is called "deepening phase" and lasts 3 years, more exactly, 6 semesters during which the surgical student works in different departments. Indeed, our practices are not univocal and it is of interest to learn different modalities by working in departments that practice the same specialty in different manners. One or two of these six semesters must be spent in specialties that are "adjacent" to ours such as pediatric surgery, or cardiovascular and thoracic surgery, or urology. Throughout this second phase, practical teaching will be dominant but our new "young learners" will continue to attend theoretical classes two half-days per week. This phase is the most important for learning surgical techniques. It is here that the learners will acquire their manual technics, sharpen their skills and for that, they will attend simulations or practical sessions on cadavers or large animals when available. This deepening phase will also be the opportunity to attend optional so-called "transversal" training such as "mass-casualty care". The dramatic terrorist attacks in November 2015 in Paris taught us that such care can no longer be the prerogative of military surgeons.

Finally, 4 years of learning is followed by a consolidation phase. It lasts 2 years. Two times 1 year in a department where the student, now a junior surgeon, will practice in a more autonomous manner. He or she will conduct surgical procedures with the always possible recourse of a senior surgeon. What makes this last phase very innovative is an opening to "optional" training. The law states that a digestive surgeon can learn surgical endoscopy! A revolution! Why? Because the use of endoscopes, until now reserved for gastroenterologists, will open the door to learning natural orifice transluminal endoscopic surgery (NOTES). The organization of learning digestive surgery is represented in Fig. 1.

The reform in postgraduate surgical training is not a simple reformatting. It is an upheaval, both for students and for teachers. All that the surgeon in training must learn and know at the end of his training is written into the law and, thus, opposable if the training objectives are not achieved. Therefore, we will have to formalize the transmission of knowledge, take charge of our students, monitor their knowledge, dedicate a lot of our time, and for that, learn how to organize and use it more effectively. That is the cost for our students to regain a passion for digestive surgery. 

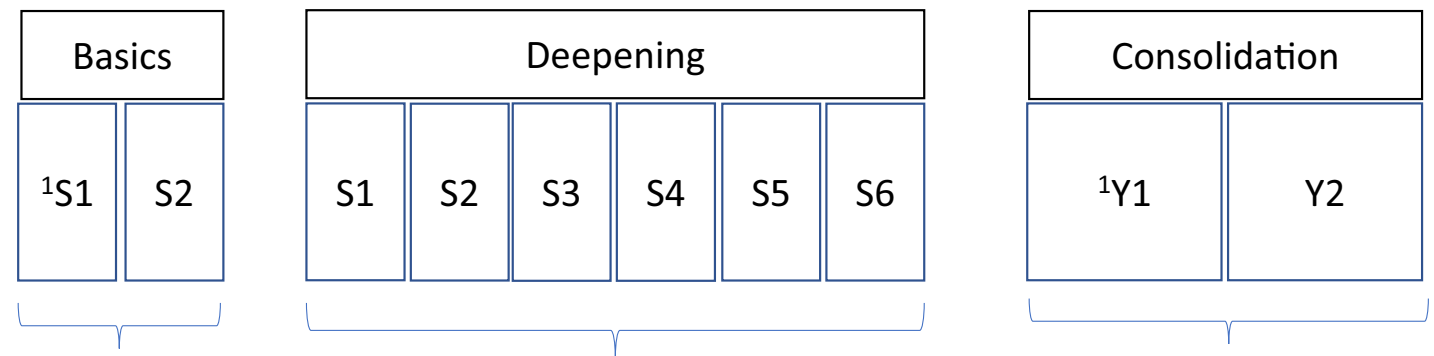

. Theory more than practice

. Basics of surgical skill

. Right to regret

.4 to 5 semesters in digestive surgery

Contract of formation

.1 or 2 semesters in adjacent specialities ${ }^{2}$

. Transversal formation ${ }^{3}$ i.e. mass-casualty care

.2 years in one or two different
departements of digestive surgery
. Grade of Junior doctor
. University hospital or not
. Optional formation
i.e. NOTES, HBP, Transplantation etc.

$1: S=$ semester $; \mathrm{Y}=$ year

2 : Urology or Cardiovascular or Thoracic surgery or Pediatric surgery

3: Optional

Fig. 1 Organization of the training of digestive surgeons in France since November 2017

\section{Compliance with ethical standards}

Conflict of interest The authors declare that they have no conflict of interest.

Study involve human and/or animals participants The research does not involve human participants and/or animals and there was no need of informed consent.

Informed consent For this type of study formal consent is not necessary.

\section{References}

1. Bessière $S$ (2005) La féminisation des professions de santé en France: données de cadrage. RFAS 1:4-15

2. Journal Officiel de la République Française. Décret n ${ }^{\circ}$ 2016-1597 du 25 novembre 2016 relatif à l'organisation du troisième cycle des études de médecine et modifiant le code de l'éducation. https ://www.legifrance.gouv.fr/eli/decret/2016/11/25/2016-1597/jo/ texte

3. Journal Officiel de la République Française. Arrêté du 12 avril 2017 portant organisation du troisième cycle des études de médecine. https://www.legifrance.gouv.fr/eli/arrete/2017/4/12/MENS1 $708241 \mathrm{~A} / \mathrm{jo} /$ texte

4. Journal Officiel de la République Française. Arrêté du 21 avril 2017 relatif aux connaissances, aux compétences et aux maquettes de formation des diplômes d'études spécialisées et fixant la liste de ces diplômes et des options et formations spécialisées transversales du troisième cycle des études de médecine. https://www. legifrance.gouv.fr/eli/arrete/2017/4/21/MENS1712264A/jo/texte

Publisher's Note Springer Nature remains neutral with regard to jurisdictional claims in published maps and institutional affiliations. 